\title{
ORALIDADE E DISCURSO JORNALÍSTICO
}

\author{
Maria Lúcia da Cunha Victório de Oliveira Andrade *
}

RESUMO: Neste trabalho, examinarei a oralidade presente no discurso escrito, recorrendo à linguagem jornalística, muito mais receptiva a transformações e exemplificando com textos dos jornais recolhidos dos jornais Folha de S. Paulo e Jornal da Tarde, bem como das revistas Veja e Isto é dinheiro. Para tanto, primeiramente farei um breve esboço sobre a linguagem jornalística contemporânea, enfocando suas principais tendências, iniciando a discussão a partir do papel dos "manuais de redação" e sua filosofia como vestígios de um purismo gramatical, nem sempre seguido à risca pelos jornalistas. A seguir, farei um paralelo entre as duas modalidades da língua: a oral e a escrita, tendo por base o material coletado e apontando as principais marcas de oralidade no discurso jornalístico. Buscarei evidenciar como tais marcas favorecem o envolvimento do jornalista com o leitor, num suposto diálogo que lembra, por vezes, a narrativa oral.

Palavras-chave: interação, linguagem formal, linguagem coloquial, marcador conversacional.

\section{AS PESQUISAS SOBRE LÍNGUA FALADA}

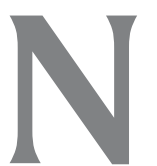

as últimas décadas, os estudiosos da Linguagem e, em especial, da Língua Portuguesa vêm acompanhando o crescimento das pesquisas sobre a língua falada, os novos processos de análise da interação verbal, os estudos de Análise da Conversação e da Sociolinguiística Interacional, bem como as contribuições da Análise do Discurso e dos trabalhos sobre a oralidade e sua presença nos vários tipos de escrita.

Mudanças de atitude linguiística, por parte dos indivíduos pertencentes à classe de prestígio, têm contribuído para que formas orais ligadas às classes populares sejam incorporadas ao uso diário da linguagem urbana. Assim, verifica-se a presença de uma linguagem mais informal na mídia, participando de veículos de comunicação, como o rádio, a televisão e a imprensa:

Universidade de São Paulo. 
"Maluf e Covas se atacam no retorno à TV" (FSP, 12/10/98);

"PSDB aliado a PT é burrice econômica" (FSP, 11/10/98);

"Negociação com o FMI dá fôlego a mercados" (FSP, 10/10/98, p.1);

"FMI: prova de confiança e início de ajuda" (JT, 10/10/98, p.1);

"Quem vence a guerra: o País ou o Judiciário? (JT, 10/10/98, p. 1)

"O número 2: com seu poder turbinado na casa civil, Clóvis Carvalho vira o senhor do palácio". (Veja, 06.01.99, p. 36)

"Queimado, mas vivo: Clinton vai a julgamento no Senado; não há, porém, votos suficientes para garantir a perda do mandato". (Veja, 06.01.99, p. 44)

"Não sou gerente da crise, diz FHC". (FSP, 02/01/99, p. 1)

“Jogada de mestre no Bradesco". (Isto é dinheiro, 03.02.99, capa)

A linguagem coloquial faz parte, de modo bem mais intenso do que no passado, das situações de comunicação mais variadas. E grande quantidade de seus vocábulos entrou para as páginas dos dicionários, ganhando status de norma lexical. Sua aceitação acabou chamando a atenção de escritores contemporâneos, como Nelson Rodrigues e Rubem Fonseca, por exemplo, que utilizaram várias marcas de oralidade em seus respectivos estilos literários.

Não cabe fazer uma crítica à propagação do discurso coloquial, pois tal atitude revelaria ignorar que todo fato linguiístico é consequiência de uma série de circunstâncias histórico-sociais, dentre as quais pode-se ressaltar as políticas, com a abertura democrática e a descaracterização progressiva da linguagem falada do povo como "inferior" e "errada". Essa linguagem adotada pelas pessoas cultas, em suas conversações diárias, tem demonstrado aos linguiistas seu caráter expressivo e, por isso, muitas vezes, uma expressão popular ou um vocábulo gírio nos surpreende sob o ponto de vista comunicativo e torna-se, em determinados contextos, a melhor forma de expressar algumas idéias, pelo menos, na linguagem oral.

Neste artigo, procurarei abordar esses aspectos, recorrendo à linguagem jornalística, muito mais receptiva a essas transformações e 
exemplificando com textos recolhidos dos jornais Folha de S. Paulo e Jornal da Tarde, bem como das revistas Veja e Isto é dinheiro. Para tanto, primeiramente farei um breve esboço da linguagem jornalística contemporânea, enfocando suas principais tendências, iniciando a discussão a partir do papel dos "manuais de redação" e sua filosofia como vestígios de um purismo gramatical, nem sempre seguido à risca pelos jornalistas. A seguir, farei um paralelo entre as duas modalidades da língua: a oral e a escrita, tendo por base o material coletado e apontando as principais marcas da oralidade no discurso jornalístico. Buscarei evidenciar como tais marcas favorecem o envolvimento do jornalista com o leitor, num suposto diálogo que lembra, por vezes, a narrativa oral.

\section{TENDÊNCIAS DA LINGUAGGM JORNALISTICA CONTEMPORÂNEA}

Como é sabido, a linguagem jornalística compõe-se de uma conjugação de diversas linguagens: a linguagem verbal escrita, a fotográfica, a gráfica e a diagramática (que se refere aos diagramas de distribuição da informação no espaço da página) (Santaella, 1992). Esta análise restringe-se à linguagem verbal escrita, mais especificamente, à questão dos registros de linguagem. Assim, para que pudéssemos ter uma noção da linguagem jornalística contemporânea, seria necessário observar os diversos jornais brasileiros urbanos e as tendências que, em linhas gerais, distribuem-se devido às características do público leitor ao qual o jornal se dirige e da ideologia política do periódico, presente na linguagem que a manifesta, como bem observa Lage (1990).

No que diz respeito apenas à linguagem verbal, podemos dizer que existem, por parte dos grandes jornais paulistanos, alguns que procuram organizar-se em termos de uma linguagem formal, culta e, para tanto, têm editado "manuais de redação" com informações e instruções para seus redatores. Por outro lado, há outros que, na busca de maior aproximação com o leitor das classes mais modestas da população, optam por uma linguagem popular. São os jornais que, na visão de Dias (1996), denominam-se populares e entre os quais se situam Notícias Populares, Última Hora e Folha da Tarde. 
Pesquisas sobre a linguagem jornalística sempre fazem referência a paralelismos entre a literatura e o jornalismo, não só porque ambos se utilizam da palavra impressa, mas, principalmente, pelo fato de o jornal, em uma primeira fase, ter se espelhado no belas-letras do discurso literário. Entretanto, nos dias de hoje "o jornalismo não é literatura” (cf. Pinto, 1986, p. 67) e a linguagem jornalística caracterizase como uma espécie de "língua veicular".

Nessa perspectiva, pressupõe-se que o jornal apresente um estilo preocupado com a comunicação em todos os níveis sócio-culturais. Os extremos, purismos e vulgarismos, não costumam constar de textos como editoriais, artigos de fundo, ficando a eventualidade de tais ocorrências restrita a matérias assinadas.

Em princípio, o texto jornalístico deveria ser fiel à norma padrão culta e deveria colocar-se num espaço, ainda que vago, entre a linguagem literária e a falada:

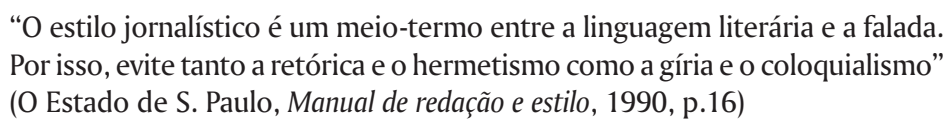

Ao ler $O$ Estado de $S$. Paulo, podemos observar que esse padrão indefinido acentua-se pela variedade de seções, sendo praticamente impossível deixar de aceitar que há leitores específicos para cada seção do jornal e que é necessário chegar à linguagem que esperam encontrar em sua leitura.

Cabe acrescentar que a concorrência entre os jornais leva-os à distinção inevitável como uma forma de obter a adesão de um público leitor específico. Nas palavras de Santaella (1992, p. 31):

\footnotetext{
"Cada jornal tenta encontrar sua própria face ou, pelo menos, traços distintivos que garantem sua faixa de público. Esta procura de face pode ter uma gama de variações que vai desde a tentativa de reversão da quantidade em qualidade, ou a intensificação de processos verbo-visuais no uso substantivo do espaçofolha, do tamanho de tipos, da integração imagem-palavra, até os jornais que manipulam sensacionalisticamente as manchetes, apelando para um público incauto que consome ficção espalhafatosa como se fosse notícia”.
} 
Ainda que a linguagem culta ("correta”, "simples", “contida”) seja apontada como aquela pretendida nos manuais, nem sempre os fatos recebem no dia-a-dia dos noticiários uma análise objetiva e fria. No tratamento de certos temas como, por exemplo, crise econômica, política ou violência social, é difícil para o jornalista redigir o seu texto empregando regras como as propostas pelo Novo manual de redação da Folha de S. Paulo (1992, p. 113):

\begin{abstract}
"O jornal reflete em seus textos o clima de tensão da maior parte dos fatos que noticia. Ela deve ser transmitida não por adjetivos, mas pela descrição seca e concisa de fatos dramáticos: Aviões de combate da força multinacional aliada iniciaram a guerra do Iraque às $2 \mathrm{~h} 30$ da manhã de hoje (21h30 de ontem Brasília). A operação "tempestade do deserto" começou à 0h58 (19h58 em Brasília), com a decolagem de caças F-15 de uma base na região central da Arábia Saudita. O secretário norte-americano de defesa, Richard Chenet, disse que participaram aviões dos E.U.A., Grã-Bretanha, Arábia Saudita e Kwait. Duas horas após o início das hostilidades, o presidente George Bush disse na TV que "a guerra começou em 2 de agosto, quando o Iraque invadiu o Kwait".
\end{abstract}

A notícia sobre a crise na lugoslávia, publicada na Folha de $S$. Paulo em 06/07/91 - Caderno Mundo, segundo Dias (op.cit., p. 41) é um bom exemplo de um texto noticioso que é exceção à regra. Nesse artigo observa-se que o clima de tensão emocional não se limita à narração direta e precisa dos fatos, mas ao uso do adjetivo ("reportagem excitante"); à presença pontual do discurso em primeira pessoa do singular e do plural ("vi tiroteios", "ficamos mais confusos"); à avaliação, inclusive com uso de vocábulo que foge à linguagem culta ("deixando os observadores malucos"); e à narração de um fato de ocorrência virtual (“... as balas passaram... quase matando um radialista português”).

Essa obrigatoriedade educativa que a imprensa assume na comunidade aponta para o grau de expectativa que o leitor tem de ver veiculada a língua oficial, culta, e não raro ocorrem situações em que os jornais se vêem obrigados a justificar deslizes em relação à língua.

Na edição de 23/05/93, o ombusdman da Folha de S. Paulo, Mário Vitor Santos, notificado sobre a frequiência de erros de concordância, regência e ortografia no jornal, reconhece que tais ocorrências com- 
prometem o padrão de qualidade e destaca como a mais importante das razões "a destruição do ensino básico no país, cujo resultado catastrófico se expressa na perda de conhecimentos e habilidades no manejo do idioma em toda a sociedade, inclusive na imprensa"(Caderno 1, p. 6).

Já na edição de 27/12/98, o atual ombusdman da Folha de S. Paulo, a jornalista Renata Lo Prete, comenta algumas cartas recebidas durante todo o ano e chama a atenção para uma em que o leitor diz ter dúvidas sobre o interesse final da função de ombusdman, já que a cada domingo lê as repetidas críticas aos erros éticos e práticos dos jornalistas da Folha, mas isso não tem sido traduzido em melhorias nos padrões do jornal, pelo contrário, parece criar uma expectativa frustrada. A jornalista se defende dizendo que "os erros se repetem, quanto a isso não há dúvida, mas mudanças de atitude, para melhor, acontecem no jornal" (Caderno 1, p. 6).

Prosseguindo com os comentários feitos pelos leitores, a jornalista acrescenta na edição de 03/01/99 que é bastante comum ouvir nas Redações "o discurso de que é preciso se preocupar com os "grandes" erros, em vez de consumir energia com deslizes pontuais" (Caderno 1, p. 10). Entretanto, acrescenta a jornalista, para o leitor as duas coisas não são excludentes. "A pesquisa constatou que incorreções factuais e de gramática têm influência decisiva sobre o grau de confiabilidade atribuído ao público" (p. 10).

Embora as justificativas dadas pelos jornalistas sejam amplas demais para os limites do questionamento do leitor, é verdade que a imprensa, de modo geral, tem procurado colocar-se como uma das responsáveis pela missão de defender a língua portuguesa. Isso se torna evidente através da divulgação dos Manuais de Redação que, entre seus objetivos, reafirmam o respeito às normas da gramática culta $\mathrm{e}$ buscam uma projeção que ultrapasse o público de jornalistas, propondo-se como auxiliares de todos os indivíduos que "precisem escrever com regularidade, estejam se preparando para exames de redação ou queiram conhecer as principais particularidades da Língua Portuguesa" (O Estado de S. Paulo, Manual de Redação e Estilo, 1990, p. 11). 
Em outubro de 1998, a Folha de S. Paulo abriu inscrições para o $28^{\circ}$. Programa de Treinamento: um curso de oito semanas que teve como objetivo "atrair novos talentos e deixá-los aptos a trabalhar em um jornal diário" (20/10/98, Cad. 1, p. 10). Dentre as atividades do treinamento, destacam-se exercícios de redação: corrigir, cortar e titular textos, reescrever reportagens de forma a torná-las mais informativas e didáticas, desenhar e montar páginas eletronicamente; exercícios de reportagem: a turma acompanha repórteres da Folha no trabalho de apuração e faz reportagens de serviço e entrevistas; aulas de português: o professor Pasquale Cipro Neto, consultor da Folha, ministrou 12 horas de aulas de português, com ênfase nos pontos em que mais se cometem erros.

Essa preocupação das empresas jornalísticas de "ensinar” a língua culta acaba por conduzir os manuais a posições nem sempre sustentáveis, em razão das leis sócio-culturais que orientam o fenômeno da variação linguiística. Do mesmo modo que as gramáticas tradicionais, essas publicações passam a ditar normas que se perdem na superficialidade, desconsiderando os contextos situacionais em que ocorrem, tornando-se, por isso, inúteis. Segundo Dias (op. cit., p. 43), "o próprio fechamento a que conduz uma classificação certo/errado contribui para a precariedade dessas leis de boa conduta linguiística, como se pode observar no Novo Manual de Redação da Folha de S. Paulo (1992, p. 270). Vejam-se alguns exemplos citados no referido manual:

- Antes de escrever: bicha, veado, fresco, boneca, traveco, sapatão, ela calça 42.

- Veja se você não quer simplesmente dizer: homossexual, travesti, lésbica.

- Mas também não exagere, escrevendo: gay (significa feliz), alfenado, safista.

A simplificação dos manuais revela a dificuldade de seus autores para discutir problemas linguísticos como o da norma e o do processo de variação sócio-cultural e geográfico da linguagem. Na verdade, essas obras divulgam, em certa medida, uma avaliação da língua extremamente discutível e talvez até pretensiosa. 
A divulgação dos manuais acaba tendo uma dupla função: se por um lado, propicia ao leitor a possibilidade de fiscalizar a execução do jornal, fazendo-o crer, por exemplo, que notícias bem escritas significam apuração dos fatos igualmente eficiente; por outro, acata a preocupação dos jornais com a formação de um público leitor específico que seja receptivo e se identifique com o discurso produzido.

Em síntese, podemos dizer que se estabelece uma relação de dupla legitimidade, de mútuo reconhecimento, com a caracterização de um enunciador autorizado a dizer e de um enunciatário apto para compreender o dito, isto é, "os que falam consideram os que escutam dignos de escutar e os que escutam consideram os que falam dignos de falar" (Bourdieu, 1983, p. 161).

\section{MARCAS DE ORALIDADE $\in$ DISCURSO JORNALÍSTICO}

Hoje, já não se pode mais pensar a língua falada e a língua escrita como modalidades invariantes. É preciso levar em conta que, no interior dessas modalidades, há variações provocadas pelas condições de produção e uso da linguagem. Conforme já apontou Castilho (1993, p. 16), qualquer correlação que se estabeleça entre ambas as modalidades deve considerá-las como "modalidades de um mesmo sistema, com ênfases diferenciadas em determinados elementos desse sistema".

Embora haja muitas diferenças entre as duas modalidades da língua, a existência de textos que se situam na faixa do contínuo pode ser constatada como bem observa Marcuschi (1993, p. 71):

\footnotetext{
"Não resta dúvida de que existem textos tipicamente orais e outros que são tipicamente escritos. Também é certo que há certos fenômenos que são mediados pela escrita e outros são mediados pela fala. As práticas sociais criam formas de transmissão do conhecimento apropriadas tanto à cultura como aos modos de produção. Estas duas classes de textos exibirão diferenças sensíveis entre si, mas os textos restantes estarão dentro da faixa de um contínuo. É até provável que não sejam muitas as diferenças essencialmente linguiísticas e que a maioria delas seja de processamento, em função do tempo, das condições e dos meios de produção, além das diferenças do tipo de texto realizado".
} 
Em suas reflexões o professor associa ao contínuo linguiístico existente entre a fala e a escrita o correlato no contínuo dos gêneros textuais e acrescenta ainda que essa variação linguístico-textual encontra similaridade na variação tipológica entre os textos falados e escritos. Veja-se, por exemplo, as relações de proximidade e diferença entre uma conversação espontânea e uma carta entre amigos ou um texto acadêmico e uma conferência universitária.

Uma leitura atenta de jornais como Folha de S. Paulo ou Jornal da Tarde, ou de revistas como Veja permite-nos observar que o narradorjornalista:

- faz uso de discurso direto, estratégia que contribui para o fator envolvimento :

\footnotetext{
"Se não corrigido a tempo, o desastre inicial poderia ter sido arrasador para a ex-paquita Letícia Spiller. Na metade do ano passado, ela foi escalada para viver Rebeca da novela das 7 Meu Bem Querer. Não gostou do papel (alguém pode culpá-la?) e acabou recusando-o. "Não era o momento, queria um trabalho no qual eu pudesse crescer”, diz. Como punição , a Globo pretendia deixá-la na geladeira por oito meses. "Fui suspensa", lamenta. Antes do fim do castigo, porém, Daniel Filho resolveu convidá-la para viver Maria Regina (...)". (Vilã recauchutada. Veja, 24/03/99, p. 135-6)
}

- aponta-nos a presença de narrador onisciente que, ao reproduzir, presumivelmente, as palavras proferidas pelo interlocutor, aproxima o texto da narrativa oral. No trecho a seguir podemos constatar essa afirmação:

\footnotetext{
"No momento do pouso, o aparelho chocou-se violentamente contra o solo, arremessando seus 36 passageiros para a frente. Com o impacto, a aeromoça sentada no fim do corredor deu uma cambalhota junto com a cadeira em que se encontrava presa pelo cinto de segurança. "O avião não aterrissou, ele praticamente caiu no chão", contou a Veja o industrial Almir Antônio Buzon, um dos 36 passageiros a bordo". (Simplesmente quebrou! Veja, 06/01/99, p. 68)
}

- Recorre ao uso de termos gírios, léxico característico da modalidade oral da língua, dado que contribui para a familiaridade do discurso, sendo também um dos responsáveis pelo fator envolvimento: 
ANDRADE, Maria Lúcia da Cunha Victório de Oliveira. Oralidade e discurso jornalístico.

"Sem feridos, o episódio ficou no limite entre o acidente e a tragédia. As companhias envolvidas, no entanto, saíram bastante chamuscadas". (Simplesmente quebrou! Veja, 06/01/99, p. 68)

"Vilã recauchutada: depois do escorregão inicial, Letícia Spiller melhora interpretação em Suave Veneno". (Veja, 24/03/99, p. 135)

"Canalha carola: Mel Gibson, que cultiva a fama de bom moço, interpreta um personagem sem caráter em 0 Troco”. (Veja, 24/03/99, p. 136)

"Chato de branco: Robin Williams, o populista, faz papel de médico de novo". (Veja, 24/03/99, p. 140)

"A crise financeira só bateu no Brasil depois de derrubar uma série de economias ao redor do planeta. Já se sabe onde a bola do desastre foi ricochetear após nocautear nossa moeda: no Equador". (Somos todos hermanos. Veja, 17/03/99, p. 52-3)

- Incorpora formas populares que integram o uso diário de uma camada específica da população, que encontra nessas manifestações linguiísticas a expressão da emoção. Observe-se o trecho a seguir:

"O ministro Clóvis Carvalho, paulista de 60 anos, é um mouro para trabalhar, um sargento para obedecer e um general para mandar - e agora, nestes últimos dias, deu para andar rindo pelos corredores. Não é à toa. Ele continua carregando uma agenda de mouro, cumprindo ordens do presidente com a mesma disciplina de sempre, mas sua alegria explica-se pelo poder de general. Mantido como ministro da Casa Civil, cargo que ocupa desde o início do governo, Clóvis Carvalho foi o único ministro a ficar no segundo mandato com mais poder do que tinha no primeiro. (... ) A exceção que chama a atenção é Clóvis Carvalho. Que já foi apelidado de "gerentão do palácio" e "bedel de ministro", e é malvisto por políticos de todos os partidos, inclusive do próprio, o PSDB, devido a sua vocação, exercitada com rigor cotidiano, de praticamente só abrir a boca para dizer "não". E mais adiante: "O Clóvis recebeu um prato tão farto que o único risco hoje é que fique intoxicado”, diz um ministro, referindo-se ao prestígio crescente do chefe da Casa Civil. Além dos encargos velhos e novos, Clóvis Carvalho tornou-se o senhor do Palácio do Planalto, abaixo apenas do próprio presidente da República”. (O número 2: com seu poder turbinado na Casa Civil, Clóvis Carvalho vira o senhor do palácio. Veja, 06/01/99, p. 36)

"Quanto mais o tempo passa, mais o papa João Paulo II capricha no visual. Em visita aos Estados Unidos em janeiro, chamou a atenção sua estola ver- 
melha de seda, enfeitada com imagens de santos. Poucas semanas depois, na missa de Quarta-Feira de Cinzas, uma profusão de bordados brilhantes emprestou ar fashion ao roxo (cor recomendada para o dia) da estola. Nada que cause muito espanto, em quem já arriscou até roupa de grife". (Papa no grito da moda. Veja, 03/03/99, p. 67)

"Parafuso solto: helicóptero envolvido na morte de empresária é proibido de voar". (Veja, 10/03/99, p. 107)

"Agito matutino: danceterias que abrem pela manhã atraem a garotada". (Veja, 17/03/99, p. 87)

"A Varig, maior e mais tradicional empresa aérea brasileira, quase aterrissou de barriga na semana passada. Pilotando um aparelho com furos de fuselagem, tanques quase vazios e uma turbina em pane, seu presidente, Fernando Pinto, encontrou pela frente uma pista cheia de obstáculos". (O tempo fechou: a crise piora na Varig e os principais executivos brigam pelo poder. Veja, 03/03/99, p. 98-9)

Além dessas manifestações, verifica-se nos textos um acentuado uso de pormenores, elemento característico do envolvimento no discurso falado. De fato, a necessidade de criar um contexto para a notícia permite ao jornalista a liberdade de arbitrar sobre a ênfase e a quantidade de pormenores.

\section{De modo geral, pode-se dizer que predomina no discurso jornalístico: \\ - oralidade marcada em algumas manchetes e no corpo de cer- tas notícias ou reportagens em que se projetam traços emocionais:}

“E agora, companheiro?” (Veja, 07/10/98, p. 34-6)

"Assim é demais!: psicólogos ganham dinheiro oferecendo consultas de até 100 reais pela internet". (Veja, 17/03/99, p. 72)

"Para nove entre dez mulheres o exame diante do espelho é sempre condenatório. Dietas, ginástica, cremes, massagens, injeções, tudo é em vão. Ela, a celulite, continua lá - buraquinhos indestrutíveis que dão às coxas e bumbum a aparência de casca de laranja. Um horror! Na semana passada as mulheres ficaram alvoroçadas. Anunciou-se, com grande estardalhaço, a chegada ao mercado americano de uma pílula anticelulite". (Puro marketing. Veja, 17/03/99, p. 119) 
ANDRADE, Maria Lúcia da Cunha Victório de Oliveira. Oralidade e discurso jornalístico.

\title{
- envolvimento do redator, conduzindo a opinião do leitor, sem- pre com uma perspectiva crítica:
}

“(...) Diante da realidade imposta pelo resultado das urnas, o espectro de um racha colossal passou a rondar com insistência a agremiação" (Veja, 07/10/98, p. 34)

"O padre que quer inovar, mas não sabe como, pode apelar para o, digamos, prêt-à-porter. Nas sete lojas da marca Apostolado Litúrgico encontram-se, ao lado de produtos nacionais com estampas indígenas ou afro, túnicas de tear típicas dos Andes, feitas no Peru e Equador - todas criadas e confeccionadas pelas freiras da Congregação Discípulas do Divino Mestre, que produz roupas litúrgicas em 29 países. (...) Inovar é permitido, contanto que sejam preservadas as cores litúrgicas: roxo, verde, branco e vermelho. Uma gama mais do que suficiente, convenhamos, para dar asas à imaginação desses servos do Senhor". (Mudança de Hábito. Veja, 03/03/99, p. 67-8)

- uma forma de transformar as notícias em narrativa, em que aparecem marcadores conversacionais e citações de fala das pessoas envolvidas:

\begin{abstract}
"E ainda remoça: pesquisa inédita revela que a prática sexual frequiente mantém a juventude" (Veja, 17/03/99, p. 118-9)

"Sexo não é só prazer. Quando bem feito, é um santo remédio. Protege o coração. Alivia o stress. E até emagrece - um orgasmo consome 160 calorias em dezenove segundos. Na semana passada, o neuropsicólogo americano David Weeks, do Hospital Real de Edimburgo, na Escócia, expandiu ainda mais esse rol de benefícios". (E ainda remoça. Veja, 17/03/99, p. 118-9)

"Depois de um dia inteiro de acusações, em que uma usina atribuía a culpa à outra, chegou a notícia do raio. De acordo com o ministério, a subestação de Bauru capta e distribui energia para São Paulo e parte do Rio de Janeiro e Minas Gerais. Como suas linhas saíram do ar, outra linha de transmissão, que sai de Itaipu e chega a Ibiúna, no interior de São Paulo, também caiu. Daí em diante, sobrecarregadas, diversas linhas de transmissão se desligaram automaticamente. (...) 'O fato é que também não existe blindagem 100\% segura', diz o secretário de Energia do Estado de São Paulo, Mauro Arce, sob cuja responsabilidade está a subestação do blecaute". (Um caos mal explicado. Veja, 17/03/99, p. 42-5).
\end{abstract}

- certa mistura entre linguagem culta e popular (oral) ou entre linguagem técnica e popular: 
Filologia e Lingüística Portuguesa, n. 3, p. 105-120, 1999.

"O ajuste fiscal de FHC vai pegar pesado na aposentadoria dos servidores públicos e aumentar o imposto sobre o cheque". (Veja, 07/10/98, p. 40-3)

"Ao gosto do freguês: Hollywood recorre às pesquisas de mercado para dar ao espectador o que ele quer ver". (Veja, 03/03/99, p. 116)

\section{- algumas frases de efeito nas manchetes:}

"A pancada que vem aî". (Veja, 07/10/98, p.40-3). Manchete relativa ao ajuste fiscal do governo.

"Você é o bolso da vez" (Veja, 10/03/99). Manchete de capa relativa ao novo pacote econômico do governo que pode gerar mais recessão e desemprego.

"O planeta grisalho: dentro de alguns meses o número de avós e bisavós nos países ricos já será maior do que o de netos e bisnetos". (Veja, 10/03/99, p. 6870)

"Farsa na corte: Elizabeth falsifica história e caráter da rainha inglesa. (Veja, 03/03/99, p. 117)

- manchetes construídas a partir de provérbios ou frases populares:

"Devagar e sempre: Cooper, o homem que colocou o mundo para correr, recomenda moderação nos exercícios”. (Veja, 24/03/99, p. 72-3).

"Dividir para reinar: respaldado por um lucro de R\$ 1 bilhão, Lázaro Brandão define sucessor e mantém-se no comando do Bradesco" (Isto é dinheiro, 03/ 02/99, p. 76-9)

"Sol e água fresca: em Paris, uma mostra celebra a leveza pop do inglês David Hockney”. (Veja, 03/03/99, p. 114-5).

\section{- Uso de termos ou expressões em inglês, francês ou espanhol:}

"Bye, bye Bob!: o deputado Roberto Campos despede-se da vida parlamentar depois de 16 anos levantando a bandeira da economia liberal. O Congresso fica mais pobre de idéias e propostas". (Isto é dinheiro, 03/02/99, p. 38-9)

"Governo leva vinte horas para justificar o maior blecaute da história e põe a culpa em um raio". (Veja, 17/03/99, p. 42-5) 
ANDRADE, Maria Lúcia da Cunha Victório de Oliveira. Oralidade e discurso jornalístico.

"Aos primeiros raios de sol do domingo o agito estava apenas começando. Mariana foi a uma after hour, uma modalidade de diversão das danceterias descoladas, que começa às 5 horas da manhã e termina na hora do almoço. (... ) Conhecidas como lounges, essas boates trocaram a pista de dança por salas decoradas com camas, pufes e sofás. Enquanto essa moda esquenta com a promessa de abertura de mais casas, os empresários já anunciam a próxima novidade, os chill-outs, festas que começam ao meio-dia e terminam às 5 da tarde. (Veja, 17/03/99, p. 87)

"Puro marketing: drágea anticelulite causa alvoroço, mas não funciona”. (Veja, 17/03/99, p. 119)

"Somos todos hermanos: terremoto econômico no Equador consolida um novo ciclo sul-americano, o da incerteza". (Veja, 17/03/99, p. 54-5)

- manchetes que relembram total ou parcialmente títulos de filmes famosos:

"Mudança de hábito: sacerdotes católicos adotam um visual colorido e arrojado para rezar missas". (Veja, 03/03/99, p. 67-8)

"O erro dos homens de branco". ( Manchete relativa aos erros cometidos por médicos. Veja, 03/03/99, p. 9)

"A vida é bela?: na violenta periferia de São Paulo, os pequenos triunfos da vida permanecem clandestinos". (Veja, 03/03/99, p. 46-9).

"Os meus, os seus, os nossos: como divórcios, separações e novos casamentos estão mudando a família brasileira". (Veja, 17/03/99, p. 108-15)

"Os arquivos X: teorias conspiratórias são o pecado original da internet. Elas divertem e assustam os internautas". (Veja, 03/03/99, p. 70-3)

"Velocidade máxima: operadoras investem US\$ 10 bi para tirar o atraso e colocar o País no primeiro mundo das comunicações". (Isto é dinheiro, 03/02/ 99, p. 50-1)

Objetivando a interação escritor/leitor, no que diz respeito ao discurso jornalístico, verifica-se a influência do discurso sobre o leitor, baseada na perspectiva segundo a qual a notícia deve ser lida dentro 
das intenções com que foi escrita. A análise de alguns textos buscou deixar claro que o uso da oralidade no discurso escrito é uma maneira eficiente de construir um texto mais envolvente para o leitor. Assim, creio que o discurso jornalístico traduz, no uso das marcas de oralidade, sua manifestação de criatividade e, por que não dizer, modernidade.

\section{BIBLIOGRAFIA}

BOURDIEU, P. (1983) A economia das trocas linguísticas. In ORTIZ, R. (org.) Pierre Bourdieu: Sociologia. São Paulo, Ática, p. 156-183.

CASTILHO, A. T. de (1993) A predicação no português falado. São Paulo, FFLCH-USP, Tese de Livre-Docência.

DIAS, A. R. F. (1996) 0 discurso da violência. São Paulo, Cortez.

LAGE, N. (1990) Linguagem jornalística 3.ed. São Paulo, Ática.

MARCUSCHI, L. A. (1993) 0 tratamento da oralidade no ensino de língua. Programa de PósGraduação em Letras e Linguiística. Recife, Universidade Federal de Pernambuco. (cópia xerox) .

PINTO, E. P. (1986) A língua escrita no Brasil. São Paulo, Ática.

SANTAELLA, L. (1992) Cultura de massas. São Paulo, Razão Social.

\section{FONTES DOCUMENTAIS}

FOLHA de S. PAULO (1992) Novo Manual da redação. São Paulo, Folha de S. Paulo.

O ESTADO de S. PAULO (1990) Manual de redação e estilo. Org. e ed. por Eduardo Martins.

São Paulo, O Estado de S. Paulo.

ABSTRACT: The purpose of this papers is to observe how the oralidade is present in the written speech, falling back upon the journalistic language, much more receptive to those transformations and exemplifying with picked up texts of the newspapers Folha de S. Paulo and Jornal da Tarde, as well as of the magazines Veja and Época. For so much, firstly I will make a brief sketch on the contemporary journalistic language, focusing its main tendencies, beginning the discussion starting from the paper of the "composition manuals" and its philosophy as vestiges of a grammatical purismo, not always proceeded precisely by the journalists. To proceed, I will make a parallel one among the two modalities of the language: the oral and the writing, tend for base the collected material and aiming the main marks of 
ANDRADE, Maria Lúcia da Cunha Victório de Oliveira. Oralidade e discurso jornalístico.

the oralidade in the journalistic speech. I will look for to evidence as such marks they favor the journalist's involvement with the reader, in a supposition dialogue that reminds, for times, the oral narrative.

Keywords: interaction, formal language, colloquial language, discourse marker. 